\title{
Correspondence
}

\section{Response to Confidentiality: a Modified Value}

SIR

Professor Emson's paper 'Confidentiality: a modified value' (1) sets out to argue that confidentiality has become eroded by such factors as multiprofessional health care, and the issuance of legislative pieces purportedly directed at the protection of society, public interest or third parties. No reason for concern, for the author considers that confidentiality no longer is a highly cherished right, as shown by public indifference to medical records falling off open trucks and becoming ubiquitously disseminated; and how does Emson explain his own observation that institutional concern to reduce information leaks has substantially increased?

The complexities of the confidentiality issue are illustrated by Emson when he conflates restrictions of autonomy ('escape[d] from surveillance') with legal limitations to confidentiality ('Typhoid Mary'), or when he suggests breaching the diagnostic confidentiality of individuals suffering from AIDS, for the benefit of technicians handling their biological samples, when in fact careful labelling and preventive measures to avoid the very low risk of laboratory infection would be more judicious than compounding the problems of recruiting and handling AIDS suspects by burdening them with unrestricted disclosure.

Emson misreads my defence of intransigent and absolute confidentiality, and thus rubricates and illustrates some of the pitfalls of discussions concerning this subject:

1. In my article (2), I explicitly stated my distrust of absolute moral values and took confidentiality rather as a strategy that is necessary for the adequate fulfilment of medical acts.

In fact, confidentiality is not in itself a value, as Emson suggests, it rather is a form of communication, an agreement about the tenor of interpersonal relations. It becomes normative because it intimately affects rights and values. Medicine does not function well unless a relationship of trust develops between caregiver and patient. The physician may require personal, even intimate information, which the patient can only deliver if misuse for non-clinical purposes is excluded. Thus, confidentiality is a contingent feature of medicine, but one that is only operant if unrestrictedly adhered to.

2. Emson reprimands me for dismissing the interests of innocent others too easily. He is wrong, for what I tried to do was to avoid the conflict of interests between confidentiality and harm to others by separating the two issues. The physician requires and is committed to confidentiality; the prevention of harm to others cannot occur at the cost of his clinical and therapeutic efforts, and must therefore be delegated to those not involved in medical work.

3. Professor Emson paraphrases me incorrectly; for I find in my article no 'brisk statement' about physicians' 'single minded . . . commitment to individual confidentiality', which would lead them to 'glibly evade their responsibility . . . . It might have been more accurate and less disparaging, had the author interpreted me correctly as stating that physicians cannot serve two masters at one time: if they honour confidentiality, they will have to be exempted from compulsory disclosures to the State, police, judicial systems or service companies and institutions. Should they prefer to honour these public commitments, they must in all honesty, visibly and with due anticipation let their patients know how frail their claim to confidentiality is. For ? the sake of good medicine I prefer the $\vec{A}$ first alternative, and for the sake of $\omega$ fairness, I would not have these $\vec{\overrightarrow{ }}$ decisions taken on an ad hoc basis but $v$ rather unrelentlessly and predictably 음 adhered to. If friends, priests, lawyers and banks are allowed to and capable of $\circlearrowleft$ creating a climate of trustworthiness, there is no reason why the medical profession should conform to less.

\section{References}

(1) Emson H E. Confidentiality: a modifię value. Foumal of medical ethics 1988; 1 87-90.

(2) Kottow M. Medical confidentiality is ' intransigent and absolute obligation'. fournal of medical ethics 1986; 12: 117122.

DR MICHAEL KOTTOW

Im Langen Hau 33 7000 Stuttgart 80

West Germany

\section{The physician as critic}

SIR

The necessary role of the physician as critic is intertwined with that of his patient's integrity and of himself. Freud $D$ provided a compassionate view of 을 human fallibility and the description $\mathrm{N}$ must include physicians. His writing on $\mathrm{N}$ errors and the forgetting of intentions $N$ concluded with errors of judgement:

“. . . Only for the rarest and best adjusted mind does it seem possible to 0 preserve the picture of an external $\frac{}{\Phi}$ reality, as it is perceived, against the distortion to which it is normally $\square$ subjected in its passage through the $\bar{O}$ psychical individuality of the $\overrightarrow{\mathbb{D}}$ percipient' (1).

Although it may seem at times a sword $\bar{\gamma}$ 